\title{
Loss, adaptation and new directions: The impact of arm morbidity on leisure activities following breast cancer
}

\author{
by Roanne Thomas, Thomas F. Hack, Elizabeth Quinlan, Sue Tatemichi, Anna Towers, Winkle Kwan, Baukje Miedema, Andrea
} Tilley, Rita Hamoline, Tricia Morrison

\section{ABOUT THE AUTHORS}
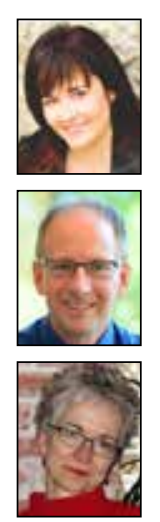

Roanne Thomas, PhD, Canada Research Chair, Professor, Faculty of Health Science, University of Ottawa, Ottawa, Ontario, Canada

Thomas F. Hack, PhD, Cpsych, University of Manitoba, Winnipeg, Manitoba, Canada; CancerCare Manitoba, Winnipeg, Manitoba, Canada

Elizabeth Quinlan, PhD, Assistant Professor, Department of Sociology, University of Saskatchewan, Saskatoon, Saskatchewan

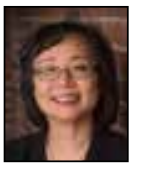

Sue Tatemichi, MSc, MD, CCFP, FCFP, Associate Professor, Family Medicine Teaching Unit, Dalhousie University, Family Medicine Teaching Unit, Dr. Everett Chalmers Hospital, Fredericton, New Brunswick

Anna Towers, MD, FCFP, Associate Professor, Department of Oncology, McGill University, Montreal, Quebec

Winkle Kwan, MBBS FRCPC, British Columbia Cancer Agency, Fraser Valley Centre, Surrey, British Columbia

Baukje Miedema, PhD, Professor \& Research Director, Department of Family Medicine, Dalhousie University, Family Medicine Teaching Unit, Dr. Everett Chalmers Hospital, Fredericton, New Brunswick

Andrea Tilley, PT, MLD/CDT, Horizon Health Network of New Brunswick, Miramichi, New Brunswick

Rita Hamoline, BA, University of Saskatchewan, Saskatoon, Saskatchewan

Tricia Morrison, PhD, OT Reg. (Ont.), University of Ottawa, Ottawa, Ontario

Address for correspondance: Dr. Roanne Thomas, Faculty of Health Sciences, University of Ottawa, 451 Smyth Road (3068),

Ottawa ON K1H 8M5; Email: roanne.thomas@uottawa.ca

Tel: 613-562-5800 (8645) / Fax: 613-562-5428

DOI: $10.5737 / 236880762514953$

\section{ABSTRACT}

The impact of arm morbidity on leisure and quality of life is an understudied area in cancer survivorship. The purpose of this study was to qualitatively describe the impact of breast cancer-related arm morbidity on leisure participation in Canadian women. A grounded theory approach was used to generate thematic categories and a model. Drawing on participants from a larger cohort study (n=740), 40 women with arm morbidity symptoms were purposively sampled and interviewed. Three themes emerged: a sense of loss, adapting participation, and new directions. Women with arm morbidity may experience an abrupt loss of previously enjoyed leisure activities and engage in a process of adapting to discover new meanings and directions. Comprehensive, person-centred cancer survivorship programs may assist with adaptation to arm morbidity.

\section{Key points}

- Psychosocial and emotional adjustment is a significant component of breast cancer recovery and coping with arm morbidity.

- Women living with arm morbidity often experience changes in their capacity to enjoy and benefit from an array of meaningful leisure activities.

- Women who experience breast cancer need to be informed of the possibility of having to negotiate with and adapt to alterations to the body and spirit, and the lifelong requirement for their adherence to advice after surgery on arm care, exercise, and diet.

T eisure time, hobbies, pastimes, and active living are inteLgral components of modern life with a variety of motivations and values such as membership in particular social groups, expressions of creativity, and notions of caring for oneself (Rojek, 2005). Leisure activities promote life balance, personal renewal, resilience, and capacity to proactively cope with stress (Fullagar, 2008; Hutchinson, Bland, \& Kleiber, 2008; Iwasaki, 2006, 2007, 2008). The literature illustrates that leisure is experienced in a variety of individually defined ways, depending on the subjective meanings and perceptions that people have (Greenwood Parr \& Lashua, 2004; Holland, 2009; Kim, 2008; Siegenthaler \& Vaughan, I998). Such activities may help to diminish negative life effects and enhance positive life attributes; leisure activities are often described as pathways to meaning-making (Rojek, 2005; Kleiber, 2002).

Cancer survivors may experience reduced opportunities to engage in leisure. In the context of breast cancer, arm morbidity (pain, range of motion restrictions, and lymphedema) affects quality of life (Hack, Cohen, Katz, Robson, \& Goss, I999; IOM, 
2007; Kwan et al., 2002; Milne, Gordon, Guilfoyle, Wallman, \& Courneya, 2007, Milne, Guilfoyle, Gordon, Wallman, \& Courneya 2007; Thomas-MacLean \& Miedema, 2005; ThomasMacLean et al., 2008). Psychosocial sequellae may manifest as a result of reduced ability to engage in leisure activities, (Edelman \& Mandle, 2006; Pedersen, Sawatzky, \& Hack, 20I0) alongside disruptions to other meaningful roles in work and family life (Quinlan et al., 20II; Radina \& Fu, 20II). Many breast cancer survivors either cease or decrease participation in leisurely activities because of the discomforts of arm morbidity (Karki, Simonen, Mälkiä, \& Selfe, 2005; Miedema et al., 2008, 20II). However, maintaining participation in leisurely activities may improve quality of life, as well as physical and mental health, among cancer survivors (Burnham \& Wilcox 2002; Kendall, MahueGiangreco, Carpenter, Ganz, \& Bernstein, 2005; McNeely et al., 2006). The connections between leisure and quality of life remain understudied, particularly from the perspectives of cancer survivors themselves. To this end, we carried out a qualitative research study documenting the effects of arm morbidity on the leisure activities of breast cancer survivors.

\section{METHODS}

\section{Participants and settings}

A sub-sample of 40 participants was selected from a larger longitudinal study across Canada that examined the physiological symptoms and psychosocial implications associated with arm morbidity of female breast cancer survivors (Thomas-MacLean et al., 2009). With approval from the research ethics boards at each site, 40 people who reported arm morbidity symptoms at the first data collection point (six to I2 months post breast cancer surgery, a timepoint selected based on clinician team members' practices, which indicated that earlier symptoms would be less likely to be chronic) were purposively sampled from this larger cohort. A sampling frame was constructed to ensure the inclusion of women with various forms of arm morbidity and to enhance demographic diversity (i.e., age, occupation). Participants ranged in age from 30 to 79. Most were engaged in professional occupations (e.g., education, health care). Significantly, I2 participants reported that they were not in the workforce. Nine women had lymphedema (measured clinically), 33 had restricted range of motion, 25 reported mild to discomforting pain, and 29 had self-reported swelling, with 3I women experiencing two or more symptoms of arm morbidity (Thomas-MacLean et al., 2009).

\section{Data collection and methods of analyses}

The research team conducted one-hour audio recorded interviews with the 40 women. The protocol for the interviews consisted of open-ended questions about topics ranging from arm symptoms to the implications for work, family, and leisure (e.g., Can you describe your arm morbidity symptoms; What has been the impact of your arm symptoms on work, hobbies, family). The interviews were then transcribed verbatim.

Proceeding with the analysis, three research team members first read all transcripts holistically with a view to learning about the effects of arm morbidity on various areas of function. Then, following established grounded theory guidelines (Bryant \& Charmaz, 2007; Charmaz, 2006) transcripts were read line by line to extract significant statements. Together, three team members identified emerging themes related to leisure (defined individually as participants' responded to questions about activities that they found enjoyable and were not related to paid work) and a coding framework for the data. To this end, NVivo 7 data analysis software was used.

\section{RESULTS}

General findings related to disability have been reported elsewhere (Thomas-Maclean et al., 2009). Herein, we focus on the changes connected to the place of leisure in the lives of women with arm morbidity after breast cancer. Three themes emerged from our data analysis: I) a sense of loss, 2) adapting participation, and 3) new directions.

\section{Theme I: A sense of loss}

First and foremost, the women grieved the loss of leisure activities. One woman, Gina (pseudonyms were assigned to all participants), summarized the deleterious impact of arm morbidity: "There [are] many things that you are not able to do, there are sports that you can't practise, there are activities that you are oblige[d] to stop." Gina suffered from arm pain and lymphedema. She tried lymphatic drainage and other treatments, but without much success. She reflected upon the losses accrued since her surgery: "After my surgery for the breast, I was really limited. Before the surgery...I was doing fitness training three times per week, I was doing roller-blading, skiing, cycling, walking, so if you compare this life with the one that I have now, now it is really boring."

Caroline also spoke of her awareness of loss. She had lost the ability to participate in identity-defining activities, as well as the comfort and pleasure of shared endeavours with her spouse. As with Gina's experience, the potential benefits of physical engagement had also been lost. The losses were, thus, multilayered for Caroline with evident significant impact, as she spoke of leisure activities in the past tense:

We're trappers. I went trapping with my husband. He had a little trap and I have a trap... I would say I was on the snow machine nearly every day. We did things together in the workshop. We'd... build, he built a lot of stuff and I used to be there helping him with lumber, plywood... I'm not as active as I used to be...I'm blaming all this on my breast cancer... my aches and pains, on my arm. I blame it all on breast cancer.

In her discussion of golf, Anne addressed the lower confidence bred by this loss - what might be viewed as an intersection between physicality and emotion:

"It is certain that with my arm, I won't be able to play golf again. I do not have the same mobility with this arm now... I was feeling good, but since a while, I am more anxious, more pensive, I do not feel in a great shape like I was not a long time ago."

For these participants, leisure carries multiple levels of meaning and significance, both at present and in the anticipated future. Arm morbidity threatens leisure in a variety of ways, including a dejected sense of boredom (Gina), a double loss of companionship and activity (Caroline) and anxiety (Anne).

Participants also had different ideas about what constituted leisure. For example, Marielle described housework in the same terms other participants used to describe more recreational pursuits: "I love to, just tidy up the house. Changing 
the bed, or whatever the case may be, I like to do my small household chores, which is not a chore for me." Snow shovelling, in particular, represented an enjoyable outdoor activity for her, one in danger of being lost:

Shovelling snow, to me, I've always loved it. And I find that it's too difficult. It's going on two years...in April, for surgery. And what if this is as good as it's going to get? It's a tough reality when you're not even 50 years old. I mean, you might have to accept the fact that this is it. This is as good as it's going to get.

A sense of accomplishment may be embedded in Marielle's pleasure in carrying out these chores. Having a diminished capacity to continue them may well have deprived her of perceived life purpose and achievement.

Participants experienced leisure in a variety of ways and intensities (see also Greenwood Parr \& Lashua, 2004; Holland, 2009; Kim, 2008; Siegenthaler \& Vaughan, 1998). Leisure was idiosyncratically defined and when participation in such meaningful activities was no longer possible, a multitude of losses were incurred. Moreover, studies have revealed that leisure activity is linked to stress relief, comfort, and personal fulfilment (Fullagar, 2008; Hutchinson et al., 2008; Iwasaki, 2006, 2007, 2008; Ormel, Lindenberg, Steverink, \& Vonkorff, I997). Thus, both the leisure literature and the present data demonstrate the impact of lost leisure activities on identity in the context of cancer survivorship.

\section{Theme 2: Adapting participation}

Several women who reported enjoying regular leisure physical activity prior to breast cancer treatment expressed their intention to maintain or regain levels of participation similar to their pre-breast cancer leisure experiences-a process of adaptation. Tracy spoke of the straining effort and doubts involved: "I am trying to adapt... I don't know how much I should use my arm. Should I use it a lot? Less? I don't know. I have a lot of questions. What could increase lymphedema? It makes me really anxious, and I will try to find answers."

Often adaptation involved creative strategies of getting around or negotiating the limitations brought on by arm morbidity. Yvonne, for instance, sought a way to continue her favourite past-time of riding horses:

I ride both Western and English and my Western saddles were old wonderful saddles, world-renowned, but they're heavy...they're around 50 pounds [and] for me to lift it on the horse, I absolutely couldn't do it anymore. So I bought a saddle of about 35 pounds [and] I can deal with it.

She added that she had not anticipated the degree of adjustment after breast cancer surgery and, upon reflection, was surprised at her naivety. While Yvonne noted a degree of loss, she also discussed the process of adapting, and this is where she began and ended her account of leisure.

Other women similarly reported finding a means to adapt to life with arm morbidity.

Sometimes this meant taking more time and being more cautious. Caroline said arm morbidity "slowed me down with my...crocheting, knitting, threading a needle, threading a sewing machine, all that." Caroline also enlisted her husband's assistance in food preparation, toward which she had mixed feelings:
He's there to help me now. I'll put everything in jars, but he'll lift the pressure cooker, or the pressure canner off the stove for me and help me take the jars out. We do it together now. As a hobby for him, a hobby for me. We do it all together. And I miss that_being by myself. It was my quiet time when I was by myself which I enjoyed.

This example illustrates that, for some women, adaptation did not necessarily mean transcendence of their disabilities, but was more often a matter of negotiation or compromise. Many participants said they had to pace and prioritize their activities in order to manage their daily lives; they used strategies such as, "do[ing] it on several days instead of one shot," "taking a break when...doing something," and "knowing when to stop and when to go." On the other hand, Mary noted that this reduced pace can have psychosocial and emotional benefits:

I mean I never stopped... it was just rush, rush, rush. Today,

I don't rush anymore. I have some leisure time. I just take my time... it is very different, but I can say that in a sense, in lots of ways I see there's less stress and I'm more peaceful and I have slowed down and, you know, I'm glad that I have slowed down... It's my choice.

In summary, then, adapting can mean a variety of positive and negative changes in a person's life. Our participants demonstrated different manners of adapting that permitted them continued participation in meaningful, enjoyable activities.

\section{Theme 3: New directions}

While some women adapted their approach to existing activities and found peace with their compromises, two found opportunity to pursue novel leisurely engagements, which they saw as transformations of their life orientation. Terry said that joining a dragon boat team with other breast cancer survivors had "given me a new something" and encouraged her to "get a kayak and try kayaking." Judy spoke of more thoughtful changes, a new approach to life that included the notion of leisure as self-caring (Rojek, 2005) and relaxation (Kleiber, 2000):

I started doing yoga, which I didn't know if I'd get into. Like, the first few days it was kind of 'Oh God, this is kind of hokey!'...But, I stuck with it and every morning I would do this...It was very calming and just focusing on that helped me relax and I think it was more a mental relaxation, metaphysical, like, it helped me more that way.

With this transformation in mind, Judy said breast cancer "kind of put things in perspective."

Both Terry and Judy discussed new directions in leisure that helped them transcend the physical and emotional challenges of arm morbidity into a self-image of positive change and growth. This may be seen as a different strategy to most of the participants, who talked less about new leisure endeavours and more about loss or preserving former activities through compromise.

\section{CONCLUSION}

As evidenced from the participants, psychosocial and emotional adjustment is a significant component of breast cancer recovery and coping with arm morbidity. Our analyses of interviews with women show that these issues intersect within the 
context of leisure activities. Women living with arm morbidity often experience changes in their capacity to enjoy and benefit from an array of meaningful leisure activities. The changes can be lifelong and range from disabling to renewing. We attempted to bring some of these changes to light in order to better guide care and rehabilitation.

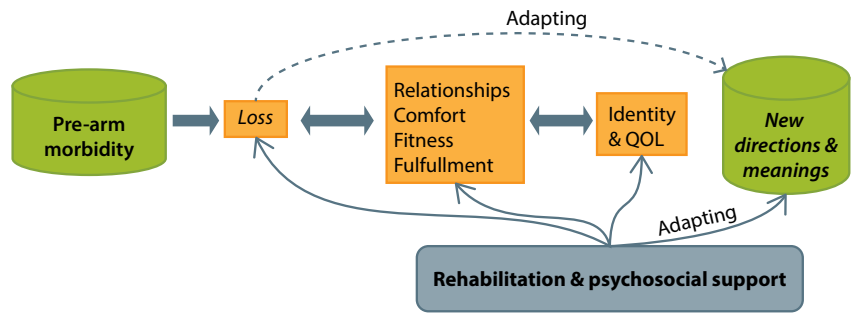

Figure I. Model of leisure participation following arm morbidity

\section{A model of leisure participation following arm morbidity}

Congruent with grounded theory, we positioned the three major themes of this study into a model of processes (see Figure I). The cylinders represent leisure participation, idiosyncratically defined by each individual, before and after arm morbidity. Leisure activities described by our participants varied widely from sports to home making and maintenance, crafts, animal care, as well as entertainment, and tended to coalesce with each individual's sense of identity. Participants reflected on various forms of loss resulting from arm morbidity and how this impacted their leisure. Losses associated with leisure were reciprocally related to disruptions in physical and emotional wellness, relationships, fulfillment and identity. The model, therefore, supports the literature that describes connections between physical health (fitness) and quality of life (Burnham $\&$ Wilcox 2002; Kendall et al., 2005; McNeely et al., 2006).

We found two major strategies for adapting to loss: many participants negotiated some form of continued involvement, while two women sought to create new life directions by pursuing novel leisurely engagements. However, many others struggled to achieve either possibility, which corresponds with quantitative data on leisure and arm morbidity (Miedema et al., 20II). This underscores a need for comprehensive rehabilitation and psychosocial support to assist survivors' processes of adapting to the full scope of arm morbidity, as indicated by the foundational box of the model (see also Davies \& Batehup, 20IO). In addition to treatment of presenting symptoms, women may benefit from more extensive preventative education about the nature, risks and consequences of arm morbidity, especially lymphedema, and the importance of regular exercise both for the affected arm itself, as well as overall health maintenance (Hack et al., 20IO; Silver \& Gilchrist, 20II). These approaches to care may be facilitated in interprofessional rehabilitation and cancer survivorship centres that can deliver appropriately tailored treatment.

\section{REFERENCES}

Burnham, T.R., \& Wilcox, A. (2002). Effects of exercise on physiological and psychological variables in cancer survivors. Medicine and Science in Sports and Exercise, 34(12), I863-1867.

\section{Implications for nursing}

Through evidence-based educational support, women who experience breast cancer need to be informed of the possibility of having to negotiate with and adapt to alterations to the body and spirit, and the lifelong requirement for their adherence to advice after surgery on arm care, exercise, diet, and other topics (Hack et al., I999; Hack et al., 20I0; Kwan et al., 2002; Radina \& Fu, 20II). Health professionals, including nurses, occupational and physical therapists, should be forthcoming with advice about potential adjustments women may need to make to accommodate these changes with the goal of enabling meaningful leisure participation, as well as the beneficial changes in perspectives and values (Silver \& Gilchrist, 20II). Further, nursing administrators may be positioned to promote access to comprehensive, person-centred, psychosocial and behavioural management and rehabilitation programs, which are needed to address the multiple and varied needs of women with arm morbidity after breast cancer (Davies \& Batehup, 20Io; Hack et al., 20IO; Quinlan et al., 20II) within the broader context of new understandings of the impact of chronic illness and disability (Livneh \& Antonak, 2005). Components of such programs could include: physiotherapy, occupational therapy, spiritual care, intimacy counselling, and nutritional counselling, as part of cancer survivorship care. Participation in such programs may reduce the degree of loss and support adaptation in all activities, including leisure.

\section{Future directions}

Participants in this study unequivocally attributed the impact on leisure to arm morbidity, but possible intersections with other phenomena such as aging and obesity would be worth exploring within the context of our theory of loss, adaptation, and new directions. While this article focuses on changes in women's leisure activities following breast cancer and the associated social processes, it should also be noted that the effects of breast cancer and associated treatment extend into multiple overlapping spheres of women's lives including the ability to participate in paid work and meaningful relationships (Quinlan et al., 20II; Radina \& Fu, 20II) and these connections would merit further research, including new studies of the model.

\section{ACKNOWLEDGEMENTS}

This research was supported by grant MOP6888 3 from the Canadian Institutes of Health Research (CIHR). This research was undertaken, in part, thanks to funding from the Canada Research Chairs program-Roanne Thomas is a Canada Research Chair in Qualitative Health Research with Marginalized Populations. Thomas F. Hack is supported by a Chair in Psychosocial and Supportive Care Oncology Research from the Prairies/NWT Region of the Canadian Breast Cancer Foundation.

Bryant, A., \& Charmaz, K. (Eds.). (2007). The Sage handbook of grounded theory. Thousand Oaks, CA.; Sage Publications Inc. 
Charmaz, K. (2006). Constructing grounded theory: A practical guide through qualitative analysis. Thousand Oaks, CA.; Sage Publications Inc.

Davies, N.J., \& Batehup, L. (2010). Self-management support for cancer survivors: Guidance for developing interventions. An update of the evidence. In D. Fenlon \& C. Foster (Eds.), Self management support: A review of the evidence-Working document to support the national cancer survivorship self management work stream. University of Southampton School of Health Sciences.

Edelman, C., \& Mandle, C. (Eds). (2006). Health promotion throughout the lifespan. St. Louis, MO.: Mosby Elsevier.

Fullagar, S. (2008). Leisure practices as counter-depressants: Emotionwork and emotion-play within women's recovery from depression. Leisure Sciences, 30(I), 35-52. doi:I0.1080/0I49040070I756345

Greenwood Parr, M., \& Lashua, B. (2004). What is leisure? The perceptions of recreation practitioners and others. Leisure Sciences, 26(I), I-I7. doi:Io.1080/0I490400490272512

Hack, T., Cohen, L., Katz, J., Robson, S., \& Goss, P. (I999). Physical and psychological morbidity after axillary lymph node dissection for breast cancer. Journal of Clinical Oncology, 17(I), I43-I49.

Hack, T., Kwan, W., Thomas-MacLean, R., Towers, A., Miedema, B., Tilley, A., \& Chateau, D. (20IO). Predictors of arm morbidity following breast cancer surgery. Psycho-Oncology, 19(II), I205-I2I2. doi:Io.I002/pon.I685

Holland, S. (2009). Preparation and determination: Three vignettes of gendered leisure. Journal of Gender Studies, 18(I), 35-45. doi:Io.1080/09589230802584246

Hutchinson, S., Bland, A., \& Kleiber, D. (2008). Leisure and stress-coping: Implications for therapeutic recreation practice. Therapeutic Recreation Journal, 4(I), 9-23.

Institute of Medicine (IOM). (2007). Cancer care for the whole patient: Meeting psychosocial health needs. Washington, DC, The National Academies Press, 2007. The Report Brief for Patients. http://www. iom.edu/Object.File/Master/47 / 600 / Psychosocial-patients\%20 Report\%2oBrief\%20FINAL3\%2oweb.pdf

Iwasaki, Y. (2006). Counteracting stress through leisure coping: A prospective health study. Psychology, Health Q Medicine, 11(2), 209220. doi:Io.IO80/13548500500I5594I

Iwasaki Y. (2007). Leisure and quality of life in an international and multicultural context: What are major pathways linking leisure to quality of life? Social Indicators Research, 82(2), 233-264. doi:I0.1007/SII205-006-9032-Z

Iwasaki, Y. (2008). Pathways to meaning-making through leisurelike pursuits in global contexts. Journal of Leisure Research, 40(2), 23I-249.

Karki, A., Simonen, R., Mälkiä, E., \& Selfe, J. (2005). Impairments, activity limitations and participation restrictions 6 and I2 months after breast cancer operation. Journal of Rehabilitation Medicine, 37(3), I80-188.

Kendall, A.R., Mahue-Giangreco, M., Carpenter, C.L., Ganz, P.A., \& Bernstein, L. (2005). Influence of exercise activity on quality of life in long-term breast cancer survivors. Quality of Life Research, 14(2), 36I-7I.

Kim, B. (2008). Research update: Perceiving leisure. Parks Q Recreation, 43(5), 24-27.

Kleiber, D. (2000). The neglect of relaxation. Journal of Leisure Research, 32(I), 82-86.

Kwan, W., Jackson, J., Weir, L., Dingee, C., McGregor, G., \& Olivotto, I. (2002). Chronic arm morbidity after curative breast cancer treatment: Prevalence and impact on quality of life. Journal of Clinical Oncology, 20(20), 4242-4248. doi:IO.I200/ JCO.2002.09.018
Livneh, H., \& Antonak, R.F. (2005). Psychosocial adaptation to chronic illness and disability: A primer for counsellors. Journal of Counselling and Development, 83(I), I2-20.

McNeely, M.L., Campbell, K.L., Rowe, B.H., Klassen, T.P., Mackey, J.R., \& Courneya, K.S. (2006). Effects of exercise on breast cancer patients and survivors: A systematic review and meta-analysis. Canadian Medical Association Journal, 175(I), 34-4I.

Miedema, B., Hamilton, R., Tatemichi, S., Thomas-MacLean, R., Towers, A., Hack, T., ... Kwan, W. (2008). Predicting recreational activities and decreased leisure activities in women 6-I2 months post breast cancer surgery. Journal of Cancer Survivorship, 2(4), 262-268. PMID: I8949564

Miedema, B., Hamilton, R., Tatemichi, S., Thomas-MacLean, R., Hack. T. F., Quinlan, E., ... Kwan, W. (20II). Do breast cancer survivors' post-surgery difficulties with recreational activities persist over time? Journal of Cancer Survivorship, 5(4), 405-4I2. doi:Io.I007/SiI764-oII-oI90-x

Milne, H., Gordon, S., Guilfoyle, A., Wallman, K., \& Courneya. K. (2007). Association between physical activity and quality of life among western Australian breast cancer survivors. PsychoOncology, 16(2), I059-I068. doi:I0.1002/pon.I2II

Milne, H., Guilfoyle, A., Gordon, S., Wallman, K., \& Courneya. K. (2007). Personal accounts of exercise and quality of life from the perspective of breast cancer survivors. Quality of Life Research 16(9), I473-I48I. doi:Io.I007/siri36-007-925I-Z

Ormel, J., Lindenberg, S., Steverink, N., \& Vonkorff, M. (I997). Quality of life and social production functions: A framework for understanding health effects. Social Science Q Medicine, 45(7), I05I-Io63. http://dx.doi.org/ıo.IoI6/So277-9536(97)00032-4

Pedersen, A., Sawatzky, J., \& Hack, T. (20I0). The sequelae of anxiety in breast cancer: A human response to illness model. Oncology Nursing Forum, 37, 469-475. doi:Io.II88/Io.ONF.469-475

Quinlan, E., MacLean, R., Hack. T., Tatemichi, S., Towers, A., Kwan, W., Miedema, B., \& Tilley, A. (20II). Breast cancer survivorship and work disability. Journal of Disability Policy Studies, 22(I), I8-27. doi:Io.II77/I044207310394439

Radina, M.E., \& Fu, M.R. (2OII). Preparing for and coping with breast cancer-related lymphedema. In A. Vannelli (Ed.), Novel strategies in lymphedema (pp. 53-88). Croatia: InTech.

Rojek, C. (2005). An outline of the action approach to leisure studies. Leisure Studies, 24(I), I3-25. doi:Io.1080/0201436042000250159

Siegenthaler, K., \& Vaughan. J. (1998). Older women in retirement communities: Perceptions of recreation and leisure. Leisure Sciences, 20(I), 53-66. doi:Io.Io80/0I490409809512264

Silver, J.K., \& Gilchrist, 1.S. (20II). Cancer rehabilitation with a focus on evidence-based outpatient physical and occupational interventions. American Journal of Physical Medicine and Rehabilitation, 90(5 Suppl.), S5-Si5.

Thomas-MacLean, R., \& Miedema, B. (2005). Feminist understandings of embodiment and disability: A 'materialdiscursive' approach to breast cancer related lymphedema. Atlantis, 30(I), 92-103.

Thomas-MacLean, R., Hack, T., Kwan, W., Miedema, B., \& Tilley, A. (2008). Arm morbidity and disability after breast cancer: New directions for care. Oncology Nursing Forum, 35(I), 65-7I. doi:Io.II88/08.ONF.65-7I

Thomas-MacLean, R., Towers, A., Quinlan, E., Hack, T., Kwan, W., Miedema, B., Tilley, A., \& Graham, P. (2009). "This is a kind of betrayal": A qualitative study of disability after breast cancer. Current Oncolog $\gamma, 16(3), 26-32$. 